\title{
Polish normalization of the Body Esteem Scale
}

\section{BACKGROUND}

Physical attractiveness plays an important part in one's social functioning. The interest in one's own appearance have been documented as widespread among the female population, but over the recent years it is more and more often emphasized that concentrating on body appearance concerns men as well. Franzoi and Shields (1984) created the Body Esteem Scale which allows to qualify the subject's attitude towards his or her own body.

The aim of the study was to create a Polish version of the Body Esteem Scale along with the norms for age and sex clusters.

\section{PARTICIPANTS AND PROCEDURE}

The normalization sample consisted of 4298 participants: 1865 women aged 16 to $80(M=29.92 ; S D=12.85)$ and 2433 men aged 16 to $78(M=28.74 ; S D=11.50)$. Education levels among the participants were also controlled for. In order to create a Polish version of the Body Esteem Scale, translation was adopted as the adaptation strategy. Like the original one, the Polish scale comprises 35 items grouped into three gender specific subscales. The subscales for women include Sexual Attractiveness, Weight Concern, and Physical Condition, whereas the body esteem of is examined with regards to Physical Attractiveness, Upper Body Strength, and Physical Condition.

\section{RESULTS}

Reliability of subscales was high both for females (Cronbach's alpha from 0.80 to 0.89 ) and males (Cronbach's alpha from 0.85 to 0.88 ).

The given coefficients of reliability cover the original division into subscales adopted by the authors of BES.

\section{CONCLUSIONS}

We confirmed high reliability of the Polish version of the Body Esteem Scale, thus we recommend it as a diagnostic tool. Created norms allowed to refer results obtained in the course of research carried out on people with various disorders (e.g. eating disorders or body dysmorphic disorder) with population data for corresponding age brackets.

\section{KEY WORDS}

body image; body esteem scale; physical appearance; self-perception; normalization 


\section{BACKGROUND}

The body seen from the psychological perspective is not a homogeneous construct. When we discuss the body, the experience or perception of it, we should mention concepts such as "body self" and "body image". Body self refers to the psychological structure which constitutes the integral part of one's self (Izydorczyk \& Bieńkowska, 2008). Body self can be defined as a way of experiencing and representing one's bodily self in one's mind and is of fundamental importance in the formation of an individual's personality (Mirucka \& Sakson-Obada, 2013). By contrast, "body image is a multifaceted psychological experience of embodiment" that encompasses evaluative thoughts, beliefs, feelings, and behaviors related to one's own physical appearance (Cash, 2004, p. 1).

Age and sex are the two factors which most significantly diversify the way the body is felt and perceived as well as the role of this process. During its first years, a child develops its own body scheme, a coherent sense of its body and beliefs concerning body image which are then used to describe one's appearance (Camões-Costa, Erjavec \& Horne, 2011). The relationship with carers and parental attitudes towards their child's looks start to outline the way the child values itself (Brownell, Zerwas \& Ramani, 2007). In the pre-school age there is a significant increase in the knowledge about the body and a feeling that the body may not be perfect can appear (Burgess \& Broome, 2012). This is the time when children start to compare themselves with others (Hayes \& Tantleff-Dunn, 2010) and dissatisfaction with one's appearance may arise (McCabe \& Ricciardelli, 2005). Regrettably, it seems that the critical attitude to the body becomes an ever-present element of self-assessment in many people. In adolescence, teenagers undergo such intense changes in their bodies that a sudden increase in interest in one's looks is not surprising; entering puberty, among other things, makes young people at risk of disturbances in body image. At that time, body image in men is less diversified than in women and it is indicated that body dissatisfaction increases among girls and decreases among boys during adolescence (Bearman, Presnell, Martinez \& Stice, 2006). Even when they are very young, girls are told that their body as an object of beauty will be closely scrutinized and will often determine how others judge their overall value in society (Mandal, 2004). Girls and young women most often report dissatisfaction with the shape of their body and insufficiently feminine looks (Lipowska \& Lipowski, 2006a). This can be linked to the progressing objective physical changes in the body, while at the same time the expectations of what the adult female body will ultimately look like are unrealistic (Rybicka-Klimczyk \& Brytek-Matera, 2008). The general developmental trend shows that the level of self-assessment changes in the course of a lifetime. After the period of reaching puberty and then adulthood, when it falls quite deeply due to external opinions (Bucchianeri et al., 2013), it gradually increases during middle adulthood (Kochan-Wójcik \& Piskorz, 2010), and on the threshold of old age it plummets as a result of confrontation with the evident signs of aging and the general, often negative opinions about old age (Ferraro et al., 2008). Not only does body image evolve with age (Tiggemann, 2004; Lipowska \& Lipowski, 2006b; Camões-Costa et al., 2011), but it can also be disrupted at any stage of experiencing one's body, which contributes, among other things, to eating disorders or body dysmorphic disorder, both in women and in men (Brytek-Matera, 2012; Hrabosky et al., 2009; Schuster, Negy \& Tantleff-Dunn, 2013).

Interest in one's own appearance has been documented as widespread among the female population (Bakhshi, 2011; Cash, Morrow, Hrabosky \& Perry, 2004; Pujols, Meston \& Seal, 2010), but over recent years it is more and more often emphasized that concentrating on body appearance concerns men as well (Tod \& Edwards, 2013). Of course, standards of beauty are different for women and men, but what also differs is their changeability over time. The ideal of the male body is subject to slower changes; since time immemorial its expected attributes have been manhood and strength (Murray \& Lewis, 2012). Demands towards women underwent considerable changes - shapely hips and an ample bosom were both desirable features in the $17^{\text {th }}$ century since they bespoke fertility and readiness for childbearing, prosperity and good health (Buss, 2001; Čabrić \& Pokrywka, 2010); the same features today are regarded as rather unwished for, up to a point of provoking questions about self-control or health (Franzoi et al., 2012; Lipowski, Buliński \& Krawczyński, 2009).

Despite different dynamics of changes in what was considered an ideal male and female body throughout the centuries, in the given period of time the model of beauty is more rigid for women. Both women and men have a "single" ideal of feminine beauty (interpreted as "the only way" to evaluate the attractiveness of the female body shape), while the choice of attractive shape of males is not so clear-cut. Although the model of beauty is stable over time, a man can be "attractive in a different way" (Szmajke, 2005). Generally men display higher levels of self-assessment associated with their appearance than women (Franzoi et al., 2012; Mandal, 2004). Currently gender differences are clear and feasible: females focus on weight and body shape while males focus on the muscular apparatus (Franzoi, 1995). Despite these differences, the desire to modify shape or weight is common to both genders. Such diversity makes it necessary to elaborate the very theoretical construct of body esteem.
Polish normalization of the Body Esteem Scale 


\section{ORIGINAL VERSION OF THE BODY ESTEEM SCALE}

Based on both the metaanalysis available in the literature of research and questionnaires as well as on their own findings, Stephen L. Franzoi and Stephanie A. Shields (1984) presented evidence that there are different domains in body esteem and these domains are relevant for females and males. Starting from this premise, they created the Body Esteem Scale, which allows one to qualify the subject's attitude towards
Małgorzata Lipowska, Mariusz Lipowski his or her own body. The scale comprises 35 items grouped into three, gender-specific subscales. The subscales for women include Sexual Attractiveness, Weight Concern, and Physical Condition, whereas the body esteem of men is examined with regards to Physical Attractiveness, Upper Body Strength, and Physical Condition. Each BES statement can be scored using a 5-item Likert-type scale, where 1 corresponds to having strong negative feelings, 5 to having strong positive feelings, and 3 represents a neutral midpoint (Franzoi \& Shields, 1984; Franzoi, 1994).

In women, the Sexual Attractiveness subscale refers to the perception of body components whose image cannot be modified by physical exercise (e.g. shape of lips, breasts). The attitude towards these body parts is associated with the emphasis of female sexuality, and their image can be modified solely by cosmetic procedures (e.g. makeup). In contrast, the Weight Concern subscale refers to completely different components of the appearance, namely, body parts whose image can be improved by physical exercise or diet. Finally, the third subscale, Physical Condition, pertains to such parameters as stamina, strength, and agility.

The Physical Attractiveness subscale for men is based on rating those features which, when combined, largely influence considering a man handsome. Among them are facial elements as well as body parts such as hips or feet. While it is true that the score on this scale is also affected by the evaluation of sexual organs, it is not their function or the sexual prowess that counts; as compared with women, the sexual element plays a significantly lower role in an overall view of men's physical attractiveness. By contrast, the Upper Body Strength subscale is based not only on the evaluation of individual body parts (e.g. chest or biceps) but also on their functions and skills which serve as a basis for judging a man strong and active. Similarly as in the case of women, the Physical Condition subscale refers to evaluations of endurance, strength and agility of the body.

The Body Esteem Scale very quickly gained popularity, not only because of its form, which is easy and quick to administer, but also due to its psychometric properties. Research conducted by the authors of the BES showed that results obtained with this scale are correlated with general self-esteem. Studies have been conducted to examine the internal consistency and test-retest reliability of the BES (Franzoi \& Shields, 1984; Franzoi, 1994) as well as construct, convergent, and divergent validity (Franzoi \& Herzog, 1986; Franzoi \& Shields, 1984; Thomas \& Freeman, 1990). The Body Esteem Scale was applied to research conducted on a wider population (Haas, Pawlow, Pettibone \& Segrist, 2012; Kornblau, Pearson \& Breitkopf Radecki, 2007; Lipowska \& Lipowski, 2006a; Pujols et al., 2010), but also on individuals struggling with health problems (Jung \& Forbes, 2007; Taleporos \& McCabe, 2002). Moreover, the BES is already used in many language versions (see: Franzoi \& Chang, 2002; Jorquera, Baños, Perpiñá \& Botella, 2005; Jung \& Forbes, 2007; Kowner, 2002; Lipowska \& Lipowski, 2006a; Taleporos \& McCabe, 2002); therefore we deemed it desirable to create a Polish normalization of the Body Esteem Scale. Naturally, our first step towards it was to gain the authors' permission.

\section{POLISH NORMALIZATION OF THE BODY ESTEEM SCALE}

In order to create a Polish version of the Body Esteem Scale, translation was adopted as the adaptation strategy. The original questionnaire was translated into Polish by two translators independently - an English teacher and a psychologist. Next, the translators settled upon the best Polish version, which was then subjected to back translation (into English) done by a native speaker who had not seen the original version. A bilingual translator assessed the compliance of the back translation with the original ${ }^{1}$.

The normalization sample consisted of 4298 participants: 1865 women aged 16 to $80(M=29.92$; $S D=12.85)$ and 2433 men aged 16 to $78(M=28.74$; $S D=11.50)$. Education levels among the participants were also controlled for (Table 1).

According to the authors' assumption that women and men differ in terms of factors which can be singled out, the factor analysis of the BES scale was carried out for subsamples divided by sex. Distribution of results in sex-split samples, specific subscales taken into account (Table 2), differs from normal, as the Kolmogorov-Smirnov test demonstrates (for women: Sexual Attractiveness $z=1.61 ; p=0.011$, Weight Concern $z=2.80 ; p=0.000$; Physical Condition $z=2.04$; $p=0.001$; for men: Physical Attractiveness $z=2.75$; $p=0.000$; Upper Body Strength $z=3.80 ; p=0.000$; Physical Condition $z=3.07 ; p=0.000$ ).

The method of principal components analysis with Varimax rotation singles out six factors for women, assuming that the own value for each factor is greater than 1 . Together they account for $51.53 \%$ of the variance explained. The authors of the BES used the same analysis in order to isolate individual factors. 
Table 1

Descriptive statistics of levels of education (in subgroups divided by sex)

\begin{tabular}{ccccccccccc}
\hline \multirow{2}{*}{ Sex } & \multicolumn{10}{c}{ Level of education } \\
\cline { 2 - 12 } & \multicolumn{2}{c}{ Primary } & \multicolumn{1}{c}{ Secondary } & \multicolumn{2}{c}{ Students } & Graduates & Full \\
\hline Female & 217 & $11.6 \%$ & 648 & $34.7 \%$ & 477 & $25.6 \%$ & 523 & $28.0 \%$ & 1865 & $100 \%$ \\
Male & 432 & $17.8 \%$ & 936 & $38.5 \%$ & 470 & $19.3 \%$ & 595 & $24.5 \%$ & 2433 & $100 \%$ \\
Sum & 649 & $15.1 \%$ & 1584 & $36.9 \%$ & 947 & $22.0 \%$ & 1118 & $26.0 \%$ & 4298 & $100 \%$ \\
\hline
\end{tabular}

Table 2

Descriptive statistics of total results for individual subscales (in subgroups divided by sex)

\begin{tabular}{ccccc}
\hline Subscales & \multicolumn{2}{c}{ Females $(n=1865)$} & \multicolumn{2}{c}{ Males $(n=2433)$} \\
\cline { 2 - 5 } & $M$ & $S D$ & $M$ & 6.56 \\
\hline Sexual Attractiveness/Physical Attractiveness & 48.86 & 7.05 & 40.48 & 5.86 \\
Weight Concern/Upper Body Strength & 32.64 & 8.45 & 33.97 & 8.42 \\
\hline Physical Condition/Physical Condition & 32.96 & 5.69 & 48.30 & 8.96 \\
\hline
\end{tabular}

- Items grouped in the first factor were as follows: figure, hips, body build, weight, legs, thighs, buttocks, waist, stomach.

- Items belonging to the second factor were: physical stamina, physical coordination, muscular strength, energy level, reflexes, physical condition, health, agility.

- Items included in the third factor were: biceps, width of shoulders, chin, arms, ears.

- Items grouped in the fourth factor were: appearance of eyes, cheeks/cheekbones, breasts, lips, face, arms.

- Items belonging to the fifth factor were: sex drive, sex activities, sex organs, feet.

- Items included in the sixth factor were: body scent, appetite, nose, body hair.

All items load on respective factors with a load value greater than 0.365 . The "arms" item loads on both the third and the fourth factor, although the third factor is loaded on more strongly. However, the scree plot (Figure 1) allows for singling out three factors. Such an

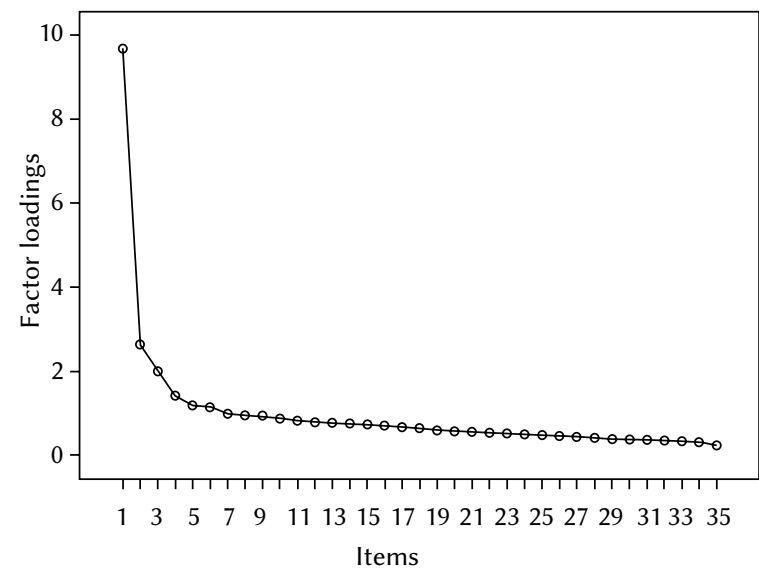

Figure 1. Scree plot - factor analysis for females. interpretation of the analysis is closer to the original assumptions for the tool, as Franzoi and Shields also obtained three factors. Therefore the authors of this work decided to adopt a three-factor solution.

The rotated components matrix, when the number of extracted factors is set at 3, explains $40.85 \%$ of total variance $(36.00 \%$ of variance for the original scale). The factor analysis showed that items grouped in the first factor were: figure (physique), body build, weight, hips, thighs, legs, waist, buttocks, stomach, appetite; those grouped in the second factor were: arms, cheeks/cheekbones, appearance of eyes, face, sex organs, chin, biceps, ears, feet, width of shoulders, breasts (chest), lips, nose, body scent, body hair, sex drive; and those grouped in the third factor were: physical stamina, physical coordination, energy level, muscular strength, reflexes, physical condition, health, sex drive, sex activities, agility.

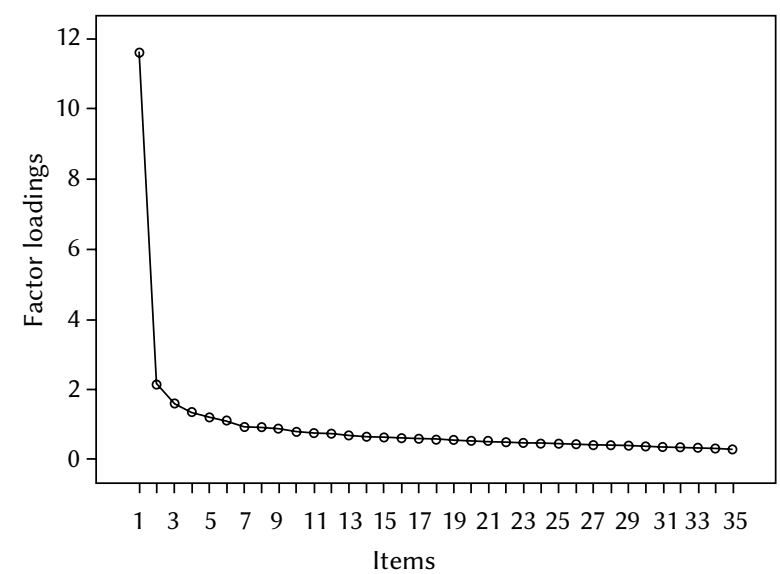

Figure 2. Scree plot - factor analysis for males.
Polish normalization of the Body Esteem Scale 
Table 3

BES items and their load values for females and males

\begin{tabular}{|c|c|c|c|c|}
\hline \multirow[t]{2}{*}{ No. } & Items & \multicolumn{3}{|c|}{ Factor loading } \\
\hline & Females (Males) & $\begin{array}{c}\text { Sexual } \\
\text { Attractiveness } \\
\text { (Physical } \\
\text { Attractiveness) }\end{array}$ & $\begin{array}{l}\text { Weight Concern } \\
\text { (Upper Body } \\
\text { Strength) }\end{array}$ & $\begin{array}{l}\text { Physical Condition } \\
\text { (Physical Condition) }\end{array}$ \\
\hline 1 & body scent & $0.38(0.39)$ & & \\
\hline 2 & appetite & & 0.26 & $(0.44)$ \\
\hline 3 & nose & $0.39(0.47)$ & & \\
\hline 4 & physical stamina & & & $0.74(0.65)$ \\
\hline 5 & reflexes & & & $0.60(0.64)$ \\
\hline 6 & lips & $0.44(0.56)$ & & \\
\hline 7 & muscular strength & & & $0.63(0.60)$ \\
\hline 8 & waist & & $0.64(0.68)$ & \\
\hline 9 & energy level & & & $0.64(0.58)$ \\
\hline 10 & thighs & & $0.68(0.63)$ & \\
\hline 11 & ears & $0.54(0.57)$ & & \\
\hline 12 & biceps & $0.54(0.50)$ & & \\
\hline 13 & chin & $0.55(0.64)$ & & \\
\hline 14 & body build & & $0.80(0.67)$ & \\
\hline 15 & physical coordination & & & $0.69(0.59)$ \\
\hline 16 & buttocks & $(0.44)$ & $0.61(0.49)$ & \\
\hline 17 & agility & & & $0.43(0.41)$ \\
\hline 18 & width of shoulders & $0.50(0.49)$ & & \\
\hline 19 & arms & $0.61(0.54)$ & & \\
\hline 20 & breasts (chest) & $0.46(0.44)$ & & \\
\hline 21 & appearance of eyes & $0.58(0.63)$ & & \\
\hline 22 & cheeks/cheekbones & $0.61(0.68)$ & & \\
\hline 23 & hips & $(0.45)$ & $0.74(0.53)$ & \\
\hline 24 & legs & $(0.45)$ & $0.68(0.55)$ & \\
\hline 25 & figure (physique) & & $0.82(0.71)$ & \\
\hline 26 & sex drive & 0.40 & & $0.44(0.64)$ \\
\hline 27 & feet & $0.51(0.64)$ & & \\
\hline 28 & sex organs & $0.56(0.47)$ & & $(0.46)$ \\
\hline 29 & stomach & & $0.61(0.60)$ & \\
\hline 30 & health & & & $0.46(0.45)$ \\
\hline 31 & sex activities & & & $0.44(0.64)$ \\
\hline 32 & body hair & $0.37(0.46)$ & & \\
\hline 33 & physical condition & & & $0.56(0.55)$ \\
\hline 34 & face & $0.57(0.54)$ & & \\
\hline 35 & weight & & $0.77(0.65)$ & \\
\hline
\end{tabular}


All items load on respective factors with a load value of more than 0.36 except for the "appetite" item, whose load value is lower. The "sex drive" item loads on both the second and the third factor.

Analogous analysis was conducted for the male group. The factor analysis using the method of principal components with Varimax rotation singled out 6 factors, assuming that the own value for each factor was greater than 1 . These six factors combined explain $54.51 \%$ of variance.

- Items grouped in the first factor were: figure (physique), stomach, weight, body build, waist, thighs, hips, legs, buttocks.

- Items belonging to the second factor were: nose, face, legs, feet, buttocks, cheeks/cheekbones, health, appearance of eyes, lips, body scent.

- Items included in the third factor were: physical stamina, reflexes, physical coordination, energy level, muscular strength, appetite, physical condition, agility.

- Items grouped in the fourth factor were: ears, chin, biceps, arms, cheeks/cheekbones.

- Items belonging to the fifth factor were: sex activities, sex drive, sex organs, body hair.

- Items included in the sixth factor were: width of shoulders, breasts (chest), muscular strength, arms.

All items load on respective factors with a load value greater than 0.33 . The following items load on two factors: hips, cheeks/cheekbones, muscular strength, arms, legs and buttocks.

The scree plot (Figure 2), however, allows for singling out three factors - similarly as for the female group.

The rotated components matrix, when the number of extracted factors is set at 3, explains $44.04 \%$ of total variance. A three-factor solution adopted for the original scale accounted for $39.00 \%$ of total variance explained. The factor analysis showed that items included as part of the first factor were: cheeks/cheekbones, chin, feet, appearance of eyes, ears, lips, face, arms, biceps, width of shoulders, sex organs, nose, body hair, breasts (chest), body scent, legs, hips, buttocks; those included as part of the second factor were: physical stamina, reflexes, sex drive, sex activities, muscular strength, physical coordination, energy level, physical condition, health, appetite, agility, sex organs; and those included as part of the third factor were: figure (physique), waist, body build, weight, thighs, stomach, legs, hips, buttocks.

All items reach more than 0.34 as their load value. The following items load on two factors with similar strength: sex organs, legs, hips and buttocks.

Table 3 presents load values of individual test items, divided into two extracted factors for both women and men.

The coefficient of reliability for the entire tool is Cronbach's alpha $=0.93$. For men this coefficient is 0.94, and for women 0.92 , which proves the high reliability of the scale. Excluding no single item would lead to considerable growth in reliability.

The coefficients of reliability for female subscales are respectively: for Sexual Attractiveness - Cronbach's alpha $=0.80$, for Weight Concern - Cronbach's alpha $=0.89$, and for Physical Condition - Cronbach's alpha $=0.82$. For male subscales the coefficients of reliability are respectively: for Physical Attractiveness - Cronbach's alpha $=0.85$, for Upper Body Strength Cronbach's alpha $=0.85$, and for Physical Condition - Cronbach's alpha $=0.88$. The given coefficients of reliability cover the original division into subscales adopted by the authors of the BES.

The analyses performed showed that psychometric properties of the Body Esteem Scale are good in respect of the studied Polish population. Nevertheless, a few differences are worth paying attention to. Results obtained amongst Polish women differed slightly from the original ones, especially in regard to items such as sex drive and sex activities. In the original version they loaded on the Sexual Attractiveness subscale, whereas in the Polish version they rather load on Physical Condition. Then in the male group: buttocks, sex activities and sex organs loaded on Physical Attractiveness in the original research while in the Polish population they also loaded on Upper Body Strength. It seems that in Poland elements connected directly with sexuality tend to be associated with condition, that is activity, rather than with appearance or attractiveness. This result coincides with data obtained by Frost (2013), who even suggested extracting yet another, fourth factor from the scale - a sexuality component. Results obtained from the Polish population are very
Polish normalization of the Body Esteem Scale

Table 4

Descriptive statistics of the sample: age cluster sizes (in subgroups divided by sex)

\begin{tabular}{|c|c|c|c|c|c|c|c|c|c|c|c|c|c|c|}
\hline \multirow{3}{*}{$\begin{array}{c}\text { Sex } \\
\text { Female }\end{array}$} & \multicolumn{14}{|c|}{ Age clusters } \\
\hline & \multicolumn{2}{|c|}{$16-19$} & \multicolumn{2}{|c|}{$20-29$} & \multicolumn{2}{|c|}{$30-39$} & \multicolumn{2}{|c|}{$40-49$} & \multicolumn{2}{|c|}{$50-59$} & \multicolumn{2}{|c|}{$60+$} & \multicolumn{2}{|c|}{ Full } \\
\hline & 395 & $21.2 \%$ & 764 & $41.0 \%$ & 312 & $16.7 \%$ & 190 & $10.2 \%$ & 132 & $7.1 \%$ & 72 & $3.9 \%$ & 1865 & $100 \%$ \\
\hline Male & 512 & $21.0 \%$ & 1055 & $43.4 \%$ & 503 & $20.7 \%$ & 204 & $8.4 \%$ & 78 & $3.2 \%$ & 81 & $3.3 \%$ & 2433 & $100 \%$ \\
\hline Sum & 907 & $21.1 \%$ & 1819 & $42.3 \%$ & 815 & $18.9 \%$ & 394 & $9.2 \%$ & 210 & $4.9 \%$ & 153 & $3.6 \%$ & 4298 & $100 \%$ \\
\hline
\end{tabular}




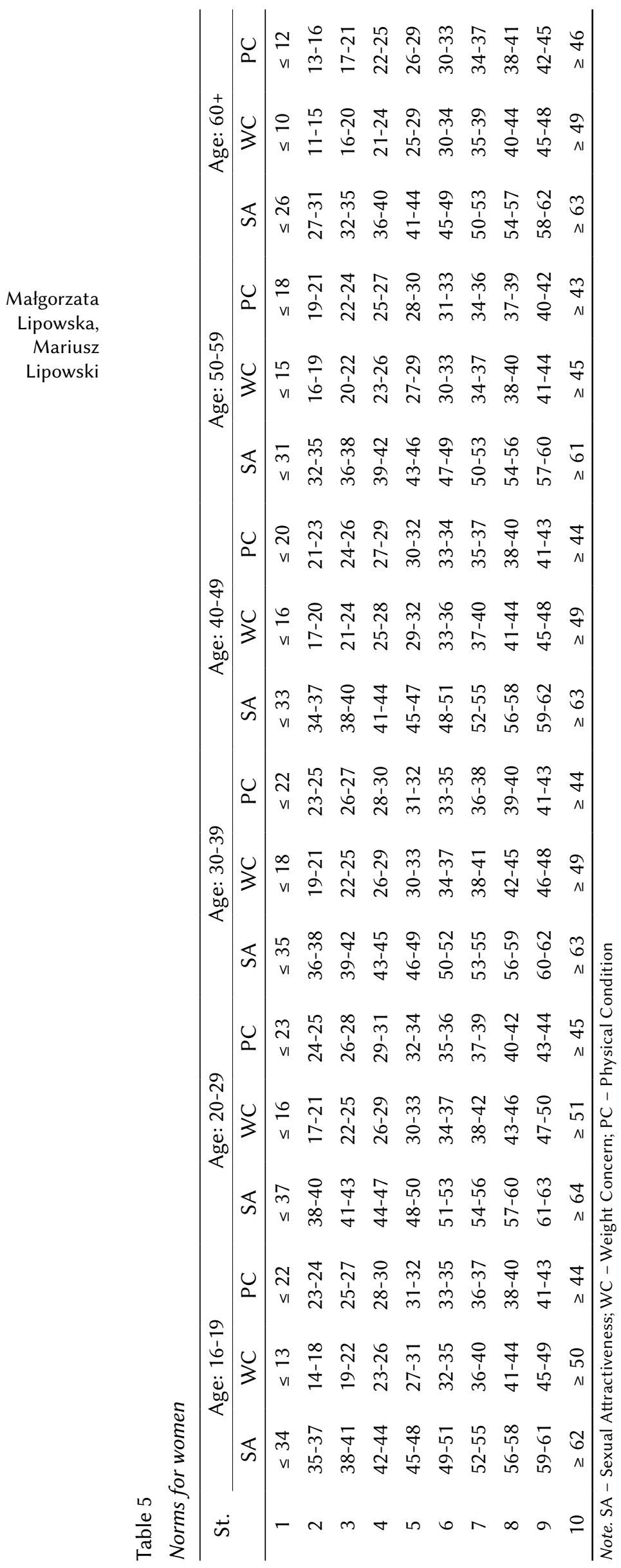

similar to the original ones, and coefficients of reliability are often even higher. Emerging differences are minor but because they have been found, a full adaptation of the scale would result in changing the number of items in individual scales. In consequence, the results obtained with the Polish version would not be fully comparable to data from other countries. Therefore we decided not to make the full adaptation of the scale, leaving all items of the Body Esteem Scale assigned to subscales identically as in the original version, and to concentrate on its standardization.

Setting norms for age and sex clusters was the next step of the procedure. Classification of age into decades was adopted during the normalization process (Table 4).

In psychology, of course, many models of periodization of ontogenetic development exist (see: Trempała, 2011). The adopted decadal system is associated not so much with the occurrence of objective, noticeable quantitative changes which would testify that the next developmental stage has begun, but rather with a tendency, deep-rooted in society, to classify people e.g. as twenty- or forty-year-olds. This classification is particularly distinct just as the public evaluation of physical attractiveness comes into play.

In the normalizing process results of 4298 participants were considered: 1865 women and 2433 men. From the normalizing sample clinical groups were excluded: persons with eating disorders, disabled. The group was diverse in terms of levels of education and age (Table 1).

Norms were calculated separately for women and men due to differences in how items load on individual factors. According to the BES underlying assumption, sexual differences are significant and therefore it was decided that the division will be implemented in the standardization, too.

The following age groups were singled out: 16-19, 20-29, 30-39, 40-49, 50-59 and 60+

The sten scale was employed when calculating the norms. This scale is popular in Poland, used not only by those related to science, but also diagnosticians and practitioners. The BES comprises 35 items, the maximum total result of which can amount to 175. The sten scale holds 10 units, which seems to be a justified choice given the number of BES items. A different scale could turn out to be unsuitable for the range of results achieved by participants.

The transformation allowing one to transfer raw data to the sten scale is given by the following formula:

$S=5.5+2 \cdot Z$

where $Z$ represents a result of the so-called Z-standardization, i.e. the expected medium value of the variable equals 0 and variance equals 1 . After the standardization of results achieved in individual sub- 
scales, raw results were converted into sten norms, where a sten result from 1 to 3 indicates a low result, from 4 to 7 a moderate result, and from 8 to 10 a high result. The result allows one to define where along the continuum "low-high body esteem" for every extracted factor a given person lies.

\section{SUMMARY}

Normalization studies conducted in Poland on a population of over four thousand participants allowed us to create norms with which it is now possible to refer results obtained in the course of research carried out on people with various disorders (e.g. eating disorders or body dysmorphic disorder) with population data for corresponding age brackets. Differences concerning which items make up extracted factors may stem from cultural differences or ongoing social changes. Some of the items (buttocks, sex activities or sex organs) are in Poland included in factors different than in the original version; it is therefore likely that in the future a change in BES structure will be advisable, one consisting in adding a sexuality component for both women and men. In spite of differences, the distribution of results in Poland, very much like the original one, made it possible to retain the clusters of items loading on individual subscales of the Body Esteem Scale, thanks to which the results obtained in Poland can be referred to research conducted worldwide.

\section{ENDNOTE}

1 A Polish version of the Body Esteem Scale questionnaire is downloadable at www.pracowniatestow.pl

\section{ReFERENCES}

Bakhshi, S. (2011). Women's body image and the role of culture: A review of the literature. Europe's Journal of Psychology, 7, 374-394.

Bearman, S.K., Presnell, K., Martinez, E. \& Stice, E. (2006). The skinny on body dissatisfaction: a longitudinal study of adolescent girls and boys. Journal of Youth and Adolescence, 35, 229-241.

Brownell, C.A., Zerwas, S. \& Ramani, G. (2007). 'So big': The development of body self-awareness in toddlers. Child Development, 78, 1426-1440.

Brytek-Matera, A. (2012). The relationship between body image disturbance and coping with stress in patients suffering from anorexia nervosa. Polish Psychological Bulletin, 43, 255-262.

Bucchianeri, M.M., Arikian, A.J., Hannan, P.J., Eisenberg, M.E. \& Neumark-Sztainer, D. (2013). Body dissatisfaction from adolescence to young adult-

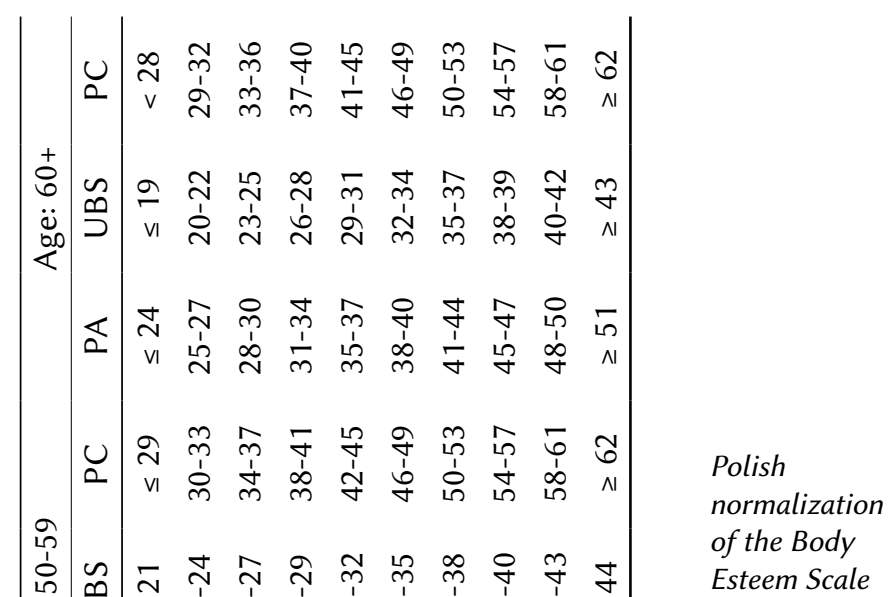

of the Body
Esteem Scale 
hood: findings from a 10-year longitudinal study. Body Image, 10, 1-7.

Burgess, J.N. \& Broome, M.E. (2012). Perceptions of weight and body image among preschool children: a pilot study. Pediatric Nursing, 38, 147-176.

Buss, D.M. (2001). Psychologia ewolucyjna [Evolutionary psychology]. Gdańsk: Gdańskie Wydawnictwo Psychologiczne.

Čabrić, M. \& Pokrywka, L. (2010). Piękno ciata [Beauty of the body]. Warszawa: Wydawnictwo Naukowe PWN.

Małgorzata

Lipowska,

Mariusz

Lipowski

Camões-Costa, V., Erjavec, M. \& Horne, P.J. (2011). Comprehension and production of body part labels in 2- to 3-year-old children. British Journal of Developmental Psychology, 29, 552-571.

Cash, T.F. (2004). Body image: Past, present, and future. Body Image, 1, 1-5.

Cash, T.F., Morrow, J.A., Hrabosky, J.I. \& Perry, A.A. (2004). How has body image changed? A cross-sectional investigation of college women and men from 1983 to 2001. Journal of Consulting and Clinical Psychology, 72, 1081-1089.

Ferraro, F.R., Muehlenkamp, J.J., Paintner, A., Wasson, K., Hager, T. \& Hoverson, F. (2008). Aging, body image, and body shape. Journal of General Psychology, 135, 379-392.

Franzoi, S.L. (1994). Further evidence of the reliability and validity of the body esteem scale. Journal of Clinical Psychology, 50, 237-239. DOI: 10.1002/1097-4679(199403)50:2<237::AID-JCLP 2270500214>3.0.CO;2-P.

Franzoi, S.L. (1995). The body-as-object versus bodyas-process: Gender differences and gender considerations. Sex Roles, 56, 13-21.

Franzoi, S.L. \& Chang, Z. (2002). The body esteem of Hmong and Caucasian young adults. Psychology of Women Quarterly, 26, 89-91. DOI: 10.1111/14716402.00046.

Franzoi, S.L. \& Herzog, M.E. (1986). The body esteem scale: A convergent and discriminant validity study. Journal of Personality Assessment, 50, 24-31. DOI:10.1207/s15327752jpa5001_4.

Franzoi, S.L. \& Shields, S.A. (1984). The body esteem scale: Multidimensional structure and sex differences in a college population. Journal of Personality Assessment, 48, 173-178. DOI: 10.1207/ s15327752jpa4802_12.

Franzoi, S.L., Vasquez, K., Sparapani, E., Frost, K., Martin, J. \& Aebly, M. (2012). Exploring body comparison tendencies: women are self-critical whereas men are self-hopeful. Psychology of Women Quarterly, 36, 99-109. DOI: $10.1177 / 0361684311427028$.

Frost, K.A. (2013). Revising the Body Esteem Scale for the next quarter century. Milwaukee: Marquette University.

Haas, C.J., Pawlow, L.A., Pettibone, J. \& Segrist, D.J. (2012). An intervention for the negative influence of media on body esteem. College Student Journal, 46, 405-418.

Hayes, S. \& Tantleff-Dunn, S. (2010). Am I too fat to be a princess? Examining the effects of popular children's media on young girls' body image. British Journal of Developmental Psychology, 28, 413-426.

Hrabosky, J.I., Cash, T.F., Veale, D., Neziroglu, F., Soll, E.A., Garn, D.M., Strachan-Kinser, M., Bakke, B., Clauss, L.J. \& Phillips, K.A. (2009). Multidimensional body image comparisons among patients with eating disorders, body dysmorphic disorder, and clinical controls: A multisite study. Body Image, 6, 155-163. DOI:10.1016/j.bodyim. 2009.03.001.

Izydorczyk, B. \& Bieńkowska, N. (2008). Obraz Ja cielesnego - wybrane teoretyczne wątki rozumienia psychologicznych mechanizmów zjawiska. Problemy Medycyny Rodzinnej, 25, 52-58.

Jorquera, M., Baños, R.M., Perpiñá, C. \& Botella, C. (2005). La Escala de Estima Corporal (BES): Validación en una muestra española. (The Body Esteem Scale (BES): Validation in a Spanish population.) Revista de Psicopatología y Psicología Clínica, 10, 173-192.

Jung, J. \& Forbes, G.B. (2007). Body dissatisfaction and disordered eating among college women in China, South Korea, and the United States: contrasting predictions from sociocultural and feminist theories. Psychology of Women Quarterly, 31, 381-393.

Kochan-Wójcik, M. \& Piskorz, J. (2010). Zmiany w zakresie postrzegania i oceny własnego ciała wśród kobiet od okresu dojrzewania do dorosłości. Psychologia Rozwojowa, 15, 21-32.

Kornblau, I.S., Pearson, H.C. \& Breitkopf Radecki, C. (2007). Demographic, behavioral, and physical correlates of body esteem among low-income female adolescents. Journal of Adolescent Health, 41, 566-570.

Kowner, R. (2002). Japanese body image: Structure and esteem scores in a cross-cultural perspective. International Journal of Psychology, 37, 149-159. DOI: $10.1080 / 00207590143000298$.

Lipowska, M. \& Lipowski, M. (2006a). Poziom optymizmu a akceptacja własnego ciała przez kobiety w okresie adolescencji. Psychologia Rozwojowa, 11, 89-96.

Lipowska, M. \& Lipowski, M. (2006b). The evaluation of own attractiveness by females of different age. In: A. Chybicka, M. Kaźmierczak (eds.). The woman in the culture - the culture in the woman (pp. 385-402). Cracow: Oficyna Wydawnicza Impuls.

Lipowski, M., Buliński, L. \& Krawczyński, M. (2009). Physical activities among other types of health-related behaviour in people losing weight. Medical Science Monitor, 15, CR423-428.

Mandal, E. (2004). Podmiotowe i interpersonalne konsekwencje stereotypów zwiazzanych z ptcia [Intra- 
personal and intrapersonal consequences of gender stereotype]. Katowice: Wydawnictwo Uniwersytetu Śląskiego.

McCabe, M.P. \& Ricciardelli, L.A. (2005). A longitudinal study of body image and strategies to lose weight and increase muscles among children. $A p$ plied Developmental Psychology, 26, 559-577.

Mirucka, B. \& Sakson-Obada, O. (2013). Ja cielesne. Od normy do zaburzeń [Body Self. When a norm becomes a disorder]. Gdańsk: GWP.

Murray, T. \& Lewis, V. (2012). Gender-role conflict and men's body satisfaction: the moderating role of age. Psychology of Men \& Masculinity. DOI: 10.1037/a0030959.

Pujols, Y., Meston, C.M. \& Seal, B.N. (2010). The association between sexual satisfaction and body image in women. Journal of Sexual Medicine, 7, 905-916.

Rybicka-Klimczyk, A. \& Brytek-Matera, A. (2008). Wizerunek ciała i jego wymiary a aspekty behawioralne zaburzeń odżywiania u zdrowych kobiet w różnych fazach rozwojowych. Endokrynologia, Otyłość i Zaburzenia Przemiany Materii, 4, 143-151.

Schuster, E., Negy, C. \& Tantleff-Dunn, S. (2013). The effects of appearance-related commentary on body dissatisfaction, eating pathology, and body change behaviors in men. Psychology of Men \& Masculinity, 14, 76-87.

Szmajke, A. (2005). Wzorce atrakcyjności ludzkiego ciała: czy ewolucja skrzywdziła kobiety? Kolokwia Psychologiczne, 13, 145-167.

Taleporos, G. \& McCabe, M.P. (2002). Development and validation of the Physical Disability Sexual and Body Esteem Scale. Sexuality \& Disability, 20, 159-176.

Thomas, C.D. \& Freeman, R.J. (1990). The body esteem scale: Construct validity of the female subscales. Journal of Personality Assessment, 54, 204212. DOI:10.1207/s15327752jpa5401\&2_20.

Tiggemann, M. (2004). Body image across the adult life span: Stability and change. Body Image, 1, 29-41.

Tod, D. \& Edwards, C. (2013). Predicting drive for muscularity behavioural engagement from body image attitudes and emotions. Body Image, 10, 135-138.

Trempała, J. (2011) (red.). Psychologia rozwoju człowieka [Developmental psychology]. Warszawa: Wydawnictwo Naukowe PWN. 